\title{
Evaluation of Ketamine as an Adjuvant to Lidocaine in Intravenous Regional Anesthesia for Upper Limb Surgery
}

\author{
ASMAA B. OPODA, M.Sc.; MOHAMMAD I. OKAB, M.D.; NABIL A. EL-SHEIKH, M.D. and \\ SAMEH MOHAMMAD F. SADEK, M.D. \\ The Department of Anesthesia, Surgical Intensive Care and Pain Management, Faculty of Medicine, Tanta University
}

\begin{abstract}
Background: Intravenous regional anesthesia (IVRA) is used in outpatient hand surgery as an easily applicable and cost-effective technique but tourniquet pain is a limitation. Ketamine in subanesthetic dose is used as an adjuvant to IVRA to improve analgesia and to impair tourniquet pain.

Aim of Study: Is to illustrate the effect of ketamine as adjuvant to lidocaine used for IVRA in patients undergoing upper limb surgery.

Patients and Methods: This double-blind randomized controlled study was carried out on 60 patient, ASA I and II, 20-40 years, scheduled for elective minor upper limb surgery. Patients were classified into 2 groups (30 each): Group I (IVRA with lidocaine only) received $3 \mathrm{mg} / \mathrm{kg}$ lidocaine $0.5 \%$ diluted with saline to $40 \mathrm{ml}$ and group II (IVRA with lidocaine and ketamine) received $3 \mathrm{mg} / \mathrm{kg}$ lidocaine $0.5 \%$ plus $50 \mathrm{mg}$ ketamine diluted with saline to $40 \mathrm{ml}$. MAP, $\mathrm{HR}$ and $\mathrm{SpO}_{2}$ were measured before, after tourniquet application, during the surgery every 15 minute, and every 30 minutes after deflating the tourniquet. Type $\&$ duration of the operation, onset $\&$ duration of sensory \& motor block were measured. VAS was recorded at $1,2,3,6,12,18$ and $24 \mathrm{~h}$ after operation, time of first rescue analgesia, total analgesic given and any undesirable side effects.
\end{abstract}

Results: Demographic data, duration of operation and hemodynamic changes (MAP, $\mathrm{HR}$ and $\mathrm{SpO}_{2}$ ) were comparable. Onset of sensory and motor block were shorter in Group II than in Group I, but the duration of sensory and motor block was prolonged. In Group II, first dose of IV analgesic was delayed and the amount of pethidine was significantly decreased. VAS and severity of tourniquet pain in group II were significantly decreased.

Conclusion: Adding ketamine 50mg to lidocaine for IVRA has faster and prolonged sensory and motor block and delayed tourniquet pain with better quality of postoperative analgesia.

Key Words: Ketamine - Lidocaine - Intravenous regional anesthesia-Upper limb surgery.

Correspondence to: Dr. Asmaa B. Opoda, The Department of Anesthesia, Surgical Intensive Care and Pain Management, Faculty of Medicine, Tanta University

\section{Introduction}

INTRAVENOUS regional anesthesia (IVRA) is used in outpatient hand surgery as an easily applicable and cost-effective technique with clinical advantages and it is an ideal anesthetic method particularly for short lasting procedures [1]

Nevertheless, IVRA has some disadvantages including tourniquet pain. Tourniquet pain is a traditional limitation of IVRA, it manifests itself as a dull and aching pain sensation increasing in severity with duration of inflation despite an adequate regional anesthesia [2] . Providing an ideal anesthesia by overcoming these disadvantages is possible with the addition of some adjunct agents to local anesthetics. Ketamine, one of the adjunct agents used in IVRA [3]

Ketamine, a phenyl-piperidine derivative, in sub anesthetic doses, used as adjuvant to IVRA has been demonstrated successfully to improve analgesia and to impair tourniquet pain. It antagonizes NMDA receptors, decreasing post synaptic depolarization of UN myelinated C fibers. Ketamine an effective anesthetic agent for IVRA at concentrations between $0.3 \%$ and $0.5 \%$ [4]

The aim of this study is to illustrate the effect of ketamine as adjuvant to lidocaine used for intravenous regional anesthesia in patients undergoing upper limb surgery.

\section{Patients and Methods}

This double-blind randomized controlled study was carried out in Tanta University Hospitals in General Surgery Department from October 2017 to May 2018 on sixty patient, ASA I and II, 20-40 years, scheduled for elective minor upper limb surgery. All data of patients was confidential with 
secret codes and private file for each patient. After approval from ethical committee, a written informed consent obtained from all participants in this research. Each patient received an explanation to the purpose of the study.

Exclusion criteria were: Chronic pain syndrome, history of allergy to local Anesthetics (amides), limb infection, vascular insufficiency (e.g., Raynaud's disease, sickle cell disease and thrombophlebitis, coagulopathy, history of seizures, neurological or psychiatric illness).

Patients were randomly classified into two equal groups (30 patients in each): Control group (lidocaine group) and study group (lidocaine plus ketamine). Group allocation was done by a sealed opaque envelope technique.

Preoperative assessment was done by history taking, clinical examination, routine laboratory investigations (CBC, bleeding time, clotting time, liver function tests, kidney function tests).

All patients connected to basic monitor displaying the following: Heart rate (HR) using electrocardiogram (ECG), peripheral oxygen saturation $(\mathrm{SpO} 2)$ using pulse oxymeter, non-invasive blood pressure (NIBP).

The patients received premedication $45 \mathrm{~min}$ before the surgery with intramuscular $0.07 \mathrm{mg} / \mathrm{kg}$ midazolam. Two intravenous cannulas were inserted, one in the operative extremity for administration of the study drug and the other in the contralateral extremity for administration of necessary medication or fluids when indicated.

Oxygen and resuscitation drugs were ready for any side effects and complication of local anesthetic agent used that may affect cardiovascular system, central nervous system and respiratory system.

Patients were randomly classified into two groups (30 each): Group I (IVRA with lidocaine only) received $3 \mathrm{mg} / \mathrm{kg}$ lidocaine $0.5 \%$ which was diluted with saline to $40 \mathrm{ml}$ and group II (IVRA with lidocaine and ketamine) received $3 \mathrm{mg} / \mathrm{kg}$ lidocaine $0.5 \%$ plus $50 \mathrm{mg}$ ketamine was administered after dilution with saline to $40 \mathrm{ml}$.

After application of routine monitors, the operative extremity was exsanguinated by maintaining elevation and intermittent squeezing for two minutes and the forearm wrapped with Esmarch bandage. Then double tourniquet was positioned on the upper operative arm and the proximal cuff was inflated to $100 \mathrm{mmHg}$ above systolic blood pressure and Esmarch bandage was removed. Circulatory isolation of the operative forearm was confirmed by inspection of the hand and absence of radial pulse. The absence of radial artery pulse in the arm isolated from the circulation was confirmed by the disappearance of pulse oximeter waves in the index finger of the same hand. The drugs, which were previously prepared, were injected to the patients over 90s. After the injection, the sensory block was assessed every 30s by alcohol gauze test. The motor was assessed by asking the patient to bring the wrist and fingers to extension and flexion and the time of complete motor block was recorded when spontaneous movement was impossible. After complete sensory and motor blocks, the distal tourniquet was inflated to $250 \mathrm{~mm} . \mathrm{Hg}$ and the proximal tourniquet was gradually deflated. The tourniquet was not be deflated earlier than 30 minutes and it was not be inflated for more than 2 hours.

Measurements: demographic data (age, sex and weight), vital signs: Mean arterial blood pressure (MAP), heart rate (HR) and pulse oxygen saturation ( $\mathrm{SpO} 2$ ) was measured before, after tourniquet application, during the surgery every 15 minute, and every 30 minutes after deflating the tourniquet. Type and duration of the operation (min), onset of sensory block \& motor block (min), duration of sensory and motor block (min), visual analogue scale (VAS) was assessed immediately then at 1 , $2,3,6,12,18$ and $24 \mathrm{~h}$ after operation (The rescue analgesia used was intravenous injection of pethidine $0.5 \mathrm{mg} / \mathrm{kg}$ whenever demanded intraoperative (for relieving tourniquet pain) or intramuscular injection postoperatively if VAS $>3$ ). Time till administration of first rescue analgesia, total analgesic given, any undesirable side effects of the study drugs during the first 24 hours were recorded: hypotension, bradycardia, convulsions, respiratory depression, tourniquet pain and hallucination.

The primary outcome was onset time of tourniquet pain and the secondary outcomes were total amount of rescue analgesia and duration of sensory block.

The sample size calculation was performed using $\mathrm{G}$ power 3.1.9.2 and calculated at $\mathrm{N}>9$ for each studied group based on the following criteria: 95\% confidence limit, $95 \%$ power of the study, group ratio 1: 1 and a previous study [5] revealed that onset time of tourniquet pain (min), the primary outcome, of lidocaine and lidocaine ketamine were $30 \pm 9.2$ and $44 \pm 6.6$ respectively.

The collected data were organized, tabulated and statistically analyzed using SPSS v25 (IBM, 
USA). For quantitative parametric data, mean and standard deviation were calculated and student $t$ test was used for comparison. For non-parametric data, median and range were calculated and MannWhitney U-test was used for comparison. For qualitative data, frequency and percentage were used and comparison was done using Chi-square test $\left(\mathrm{X}_{2}\right)$. The level of significance was adapted at $p$-value $<0.05$.

\section{Results}

In this study, 59 patients were assessed for eligibility; 7 patients did not meet the inclusion criteria and 2 patients refused to participate in the study. 60 patients were randomized into two groups 30 patients in each one; Group I: IVRA with lidocaine only and Group II: IVRA with lidocaine and ketamine. All patients are followed-up and analyzed Fig. (1).

In our study, there was no statistically significant difference as regard Demographic data (Age, weight and Gender), duration of operation and in hemodynamic changes (MAP, HR and $\mathrm{SpO}_{2}$ ).

For onset of sensory and motor block it is found to be shorter in Group II than in Group I, and the duration of sensory and motor block it was found to be prolonged in Group II than in group I technique. As regard the first dose of IV analgesic it was earlier in Group I than in Group II and the amount of given analgesia in group II was significantly decreased than in Group I.
VAS in group II immediately then at 1, 2, 3, 6 , 12,18 and $24 \mathrm{~h}$ after operation were significantly decreased than in group I. As regard of severity of tourniquet pain in Group II was significantly decreased than in Group I.

Table (1): Patients' demographic data of the studied groups.

\begin{tabular}{llll}
\hline & \multicolumn{1}{c}{$\begin{array}{c}\text { Group I } \\
(\mathrm{n}=30)\end{array}$} & $\begin{array}{c}\text { Group II } \\
(\mathrm{n}=30)\end{array}$ & $\begin{array}{c}p- \\
\text { value }\end{array}$ \\
\hline Age (years) & $31.46-\{9.24$ & $31.53-\} 7.56$ & 0.9757 \\
Weight (Kg) & $85.8-\} 8.64$ & $85.16-\} 9.29$ & 0.7856 \\
$\begin{array}{l}\text { Duration of surgery } \\
\text { (min) }\end{array}$ & $42.96-\} 4.74$ & $45-\{5.62$ & 0.141 \\
Gender (Male/Female) & $14 / 16$ & $13 / 17$ & 0.7952 \\
\hline
\end{tabular}

Table (2): Onset \& duration of sensory \& motor block, onset of tourniquet pain \& 1 st dose of analgesic requirements and total dose of rescue analgesia.

\begin{tabular}{lllc}
\hline & $\begin{array}{c}\text { Group I } \\
(\mathrm{n}=30)\end{array}$ & $\begin{array}{c}\text { Group II } \\
(\mathrm{n}=30)\end{array}$ & $\begin{array}{c}p- \\
\text { value }\end{array}$ \\
\hline $\begin{array}{c}\text { Onset of sensory } \\
\text { block (min) }\end{array}$ & $7.6-\} 1.08$ & $5.33-\} 1.04$ & $<0.0001$ \\
$\begin{array}{c}\text { Onset of motor block } \\
\text { (min) }\end{array}$ & $12.96-\} 0.84$ & $8.96-\} 0.84$ & $<0.0001$ \\
$\begin{array}{c}\text { Duration of sensory } \\
\text { block (min) }\end{array}$ & $48-\} 5.07$ & $52.7-\} 5.74$ & $<0.0001$ \\
$\begin{array}{c}\text { Duration of motor } \\
\text { block (min) }\end{array}$ & $48.7-\{4.80$ & $52.96-\} 5.85$ & $<0.0001$ \\
$\begin{array}{c}\text { Onset of tourniquet } \\
\text { pain (min) }\end{array}$ & $29.86-\} 5.42$ & $44.26-\{3.23$ & $<0.0001$ \\
$\begin{array}{c}\text { Onset of 1 st dose of } \\
\text { analgesic } \\
\text { requirements (min) }\end{array}$ & $37.23-\} 5.43$ & $282.76-\{28.90$ & $<0.0001$ \\
\hline $\begin{array}{c}\text { Total dose of rescue } \\
\text { analgesia } \\
\text { (pethidine in mg) }\end{array}$ & $127-\{2.61$ & $64.43-\{2.29$ & $<0.0001$ \\
\hline
\end{tabular}

Table (3): VAS in studied groups.

\begin{tabular}{|c|c|c|c|c|c|c|c|c|}
\hline $\mathrm{N}$ & Immediately & $1 \mathrm{hr}$. & $2 \mathrm{hr}$. & $3 \mathrm{hr}$. & $6 \mathrm{hr}$. & $12 \mathrm{hr}$. & $18 \mathrm{hr}$. & $24 \mathrm{hr}$. \\
\hline \multicolumn{9}{|l|}{ Group I: } \\
\hline Median & 1 & 3 & 2 & 2 & 4 & 4 & 5 & 6 \\
\hline Range & $0-2$ & $1-4$ & $1-4$ & $1-4$ & $3-5$ & $3-5$ & $4-6$ & $4-6$ \\
\hline \multicolumn{9}{|l|}{ Group II: } \\
\hline Median & 0 & 1 & 1 & 2 & 4 & 5 & 5 & 6 \\
\hline Range & $0-1$ & $0-2$ & $1-2$ & $1-2$ & $3-5$ & $3-6$ & $4-6$ & $4-6$ \\
\hline$p$-value & 0.0393 & $<0.0001$ & 0.0006 & 0.2734 & 0.4609 & 0.1203 & 0.456 & 0.148 \\
\hline
\end{tabular}

Table (4): Side effects of both groups.

\begin{tabular}{lccccccc}
\hline & \multicolumn{3}{c}{ Intraoperatively } & \multicolumn{3}{c}{ Postoperatively } \\
\cline { 2 - 7 } & Group I & Group II & $p$-value & Group I & Group II & $p$-value \\
\hline Hypotension & 2 & 1 & 0.553 & 3 & 0 & 0.236 \\
Bradycardia & 0 & 1 & 0.313 & 1 & 0 & 0.313 \\
Convulsion & 0 & 0 & - & 0 & 0 & - \\
Respiratory depression & 0 & 0 & - & 0 & 0 & - \\
Systemic toxicity & 0 & 0 & - & 0 & 0 & - \\
Hallucination & 0 & 0 & - & 0 & 0 & 1 \\
Nausea & 0 & 0 & - & 1 & 1 & 0.553 \\
Vomiting & 0 & 0 & - & 2 & 1 & 0 \\
\hline
\end{tabular}




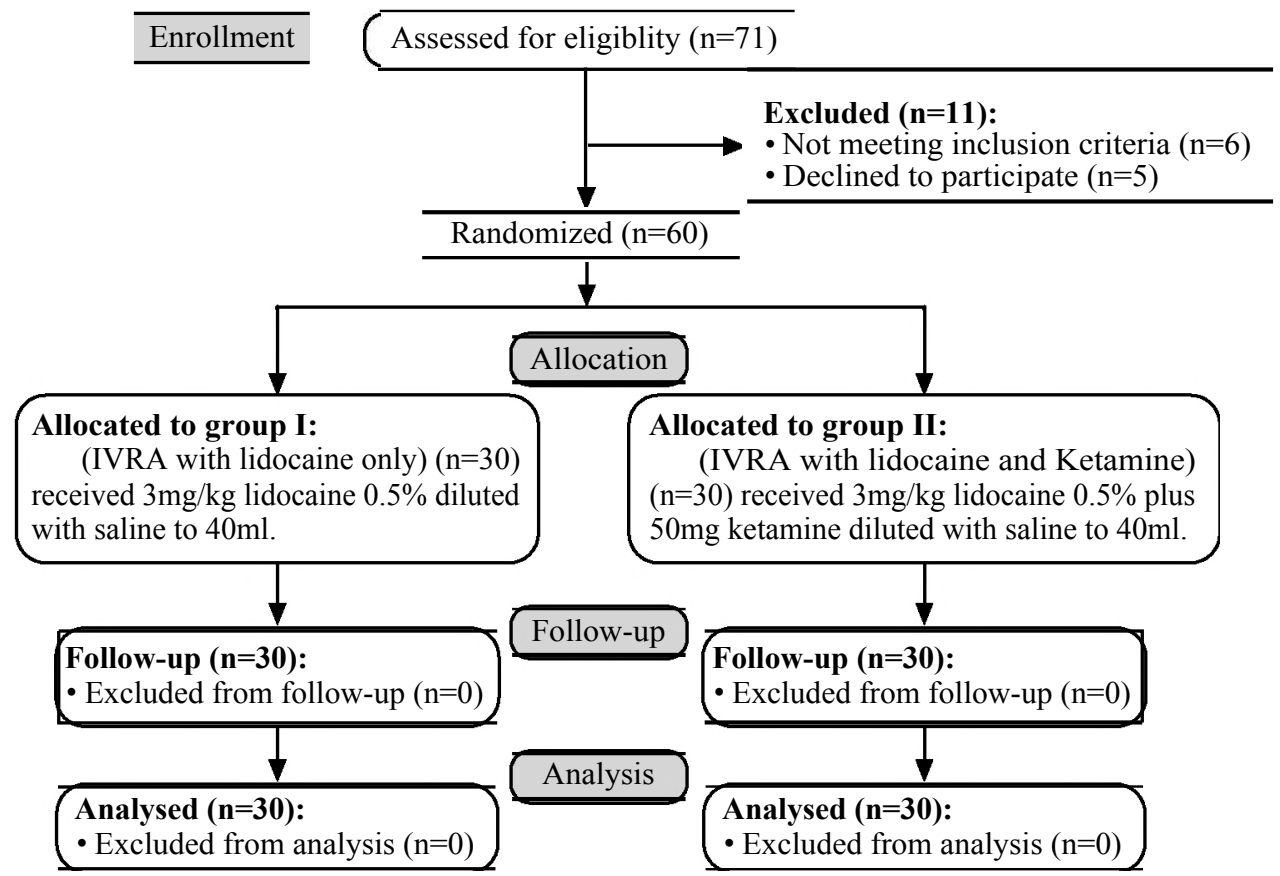

Fig. (1): Patient flowchart summarizing enrollment, allocation, follow-up and analysis in the study protocol.

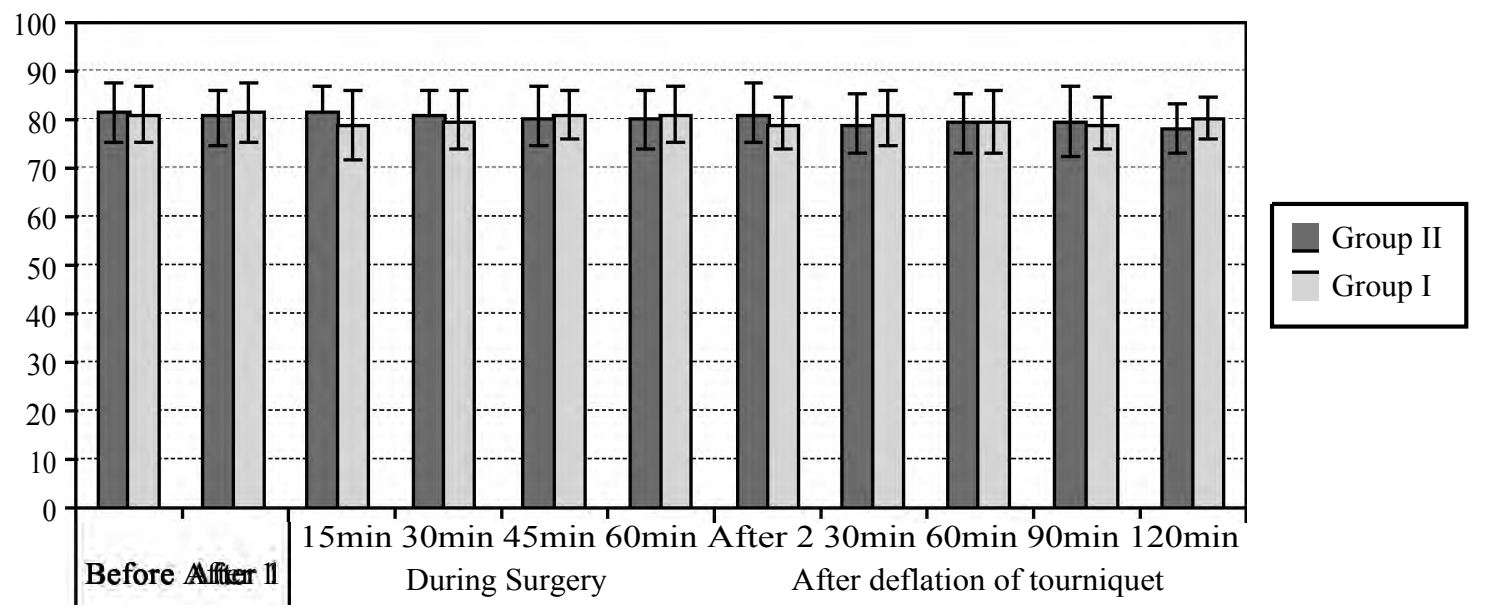

Fig. (2): Mean arterial blood pressure $(\mathrm{mmHg})$ changes in both groups.

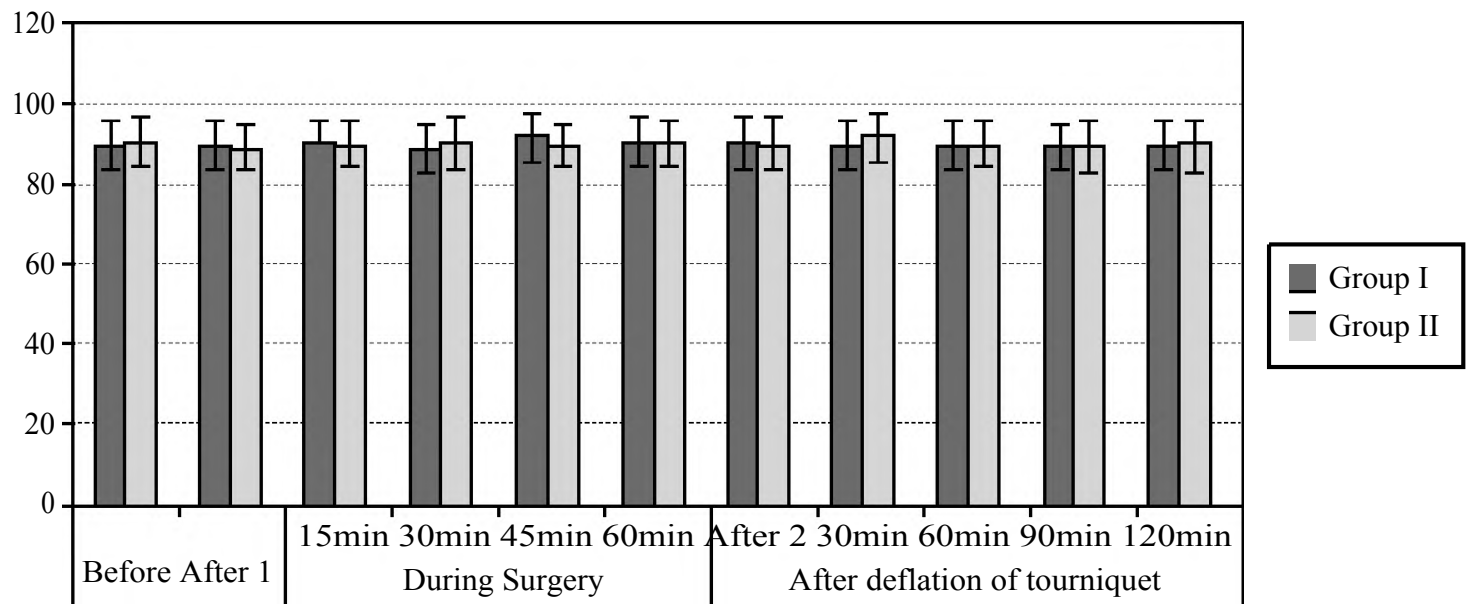

Fig. (3): Heart rate (b/min) changes in both groups. 


\section{Discussion}

Tourniquet pain may arise from ischemia of peripheral neurons of nociceptive distal to tourniquet, or from nerve fiber activation directly under it, again because ischemia. Furthermore mechanical trauma and tissue ischemia under or distal to tourniquet lead to release of inflammatory mediators and thus initiate, and/or aggravate tourniquet pain. [6].

Ketamine exerts is a noncompetitive antagonist of NMDA receptor. In addition to spinal cord, NMDA receptors have also been identified on peripheral unmyelinated sensory axons, so ketamine can attenuate the tourniquet pain via NMDA $[1,7]$

Our results show agreement with Kumar et al., also who compared the effect of dexmedetomidine and ketamine when added to lignocaine in IVRA, reported that addition of $0.5 \mathrm{mg} / \mathrm{kg}$ of body weight ketamine to lignocaine for IVRA delayed the onset of tourniquet pain, reduced the time for onset of block, reduced postoperative analgesic requirement and had a better patient satisfaction and also mentioned that two patients had restlessness in group lidocaine ketamine [8].

Also, in agreement with the study of Nikos et al., who studied addition of clonidine $1 \mathrm{Mg} / \mathrm{kg}$ or ketamine $0.1 \mathrm{mg} / \mathrm{kg}$ to lidocaine $0.5 \%$ for IVRA delays the onset of tourniquet pain and decreases analgesic consumption for tourniquet pain relief [9].

Also, Christopher et al., compares intraoperative tourniquet pain, postoperative analgesia, and side effects of systemic versus IVRA ketamine during outpatient hand surgery. It showed that intraoperative tourniquet pain and postoperative analgesia are similar if $0.1 \mathrm{mg} / \mathrm{kg}$ ketamine is added to lidocaine-based IVRA or administered via a peripheral IV line and these findings are consistent with ketamine having central and peripheral mechanisms of action [10].

Also Haider and Mahdi that found that drug combination of ketamine, atracurium and lidocaine leads to rapid onset of sensory block, motor block and lower VAS score for pain and also found that bradycardia, restlessness and muscle fasciculation had occurred and decreased by addition of ketamine or ketamine plus atracurium for IVRA [11].

Our results were in agreement with Gorgias et al., who compared the efficacy of a low dose of clonidine or ketamine separately added to intravenous regional anesthesia (IVRA) with lidocaine to prevent tourniquet pain and it reported that the addition of clonidine $1 \mathrm{Mg} / \mathrm{kg}$ or ketamine $0.1 \mathrm{mg} / \mathrm{kg}$ to lidocaine $0.5 \%$ for IVRA reduced tourniquet pain, delayed first request of analgesia and also reported side effects in the form of hallucinations in 3 patients, paresthesia in 3 patients, dizziness in 2 patients, and nausea in 1 patient [9].

Our result was in contrast with Durrani et al., who found that the use of $0.3 \%$ ketamine as a sole agent for IVRA for regional anesthesia of the upper extremity was adequate for complete sympathetic, sensory, and motor blockades and [4] .

Kaul et al., compared ketamine $(0.5 \%) 3 \mathrm{mg} / \mathrm{kg}$ with lignocaine $(0.5 \%) 3 \mathrm{mg} / \mathrm{kg}$. The onset of analgesia and motor blockade was similar in both the study groups. However, duration of analgesia after release of tourniquet was longer with ketamine. Also, the quality of analgesia was superior in the ketamine group, but all patients in the ketamine group suffered from disorientation and hallucinations [12] .

\section{Conclusion:}

Adding ketamine 50mg to lidocaine for IVRA has faster and prolonged sensory and motor block and delayed tourniquet pain with better quality of postoperative analgesia.

\section{Conflicts of interest: Nil.}

Authors' contributions: All authors had equal role.

\section{References}

1- ELMETWALY K.F., HEGAZY N.A., ABOELSEOUD A.A. and ALSHAER A.A.: Does the use of ketamine or nitroglycerin as an adjuvant to lidocaine improve the quality of intravenous regional anesthesia? Saudi J. Anaesth., 4 (2): 55-62, 2010.

2- ESTEBE J.P., LE NAOURES A., CHEMALY L. and ECOFFEY C.: Tourniquet pain in a volunteer study: Effect of changes in cuff width and pressure. Anaesthesia, 55 (1): $21-6,2000$.

3- YEKTAŞ A., GÜMÜS F., KARAYEL A. and ALAGÖL A.: Effects of addition of systemic tramadol or adjunct tramadol to lidocaine used for intravenous regional anesthesia in patients undergoing hand surgery. Anesthesiol. Res. Pract., 25-32, 2016.

4- DURRANI Z., WINNIE A.P., ZSIGMOND E.K. and BURNETT M.L.: Ketamine for intravenous regional anesthesia. Anesth. Analg., 68 (3): 328-32, 1989.

5- KRISHNA P.R. and NARAYANA C.S.: A comparitive study of plain lignocaine and lignocaine with ketamine for intravenous regional anaesthesia (ivra) for upper limb surgeries. Indian J. Appl. Res., 5 (5): 19-23, 2015.

6- SCHOEN M., ROTTER R., GIERER P., GRADL G., STRAUSS U., JONAS L., et al.: Ischemic preconditioning 
prevents skeletal muscle tissue injury, but not nerve lesion upon tourniquet-induced ischemia. J. Trauma Acute. Care Surg., 63 (4): 788-97, 2007.

7- ANDERSEN O.K., FELSBY S., NICOLAISEN L., BJERRING P., JENSEN T.S. and ARENDT-NIELSEN L.: The effect of Ketamine on stimulation of primary and secondary hyperalgesic areas induced by capsaicin-a doubleblind, placebo-controlled, human experimental study. Pain, 66 (1): 51-62, 1996.

8- KUMAR A., SHARMA D. and DATTA B.: Addition of ketamine or dexmedetomidine to lignocaine in intravenous regional anesthesia: A randomized controlled study. J. Anaesthesiol. Clin. Pharmacol., 28 (4): 501-4, 2012.

9- GORGIAS N.K., MAIDATSI P.G., KYRIAKIDIS A.M., KARAKOULAS K.A., ALVANOS D.N. and GIALA
M.M.: Clonidine versus ketamine to prevent tourniquet pain during intravenous regional anesthesia with lidocaine. Reg. Anesth. Pain. Med., 26 (6): 512-7, 2001.

10- VISCOMI C.M., FRIEND A., PARKER C., MURPHY T. and YARNELL M.: Ketamine as an adjuvant in lidocaine intravenous regional anesthesia: A randomized, double-blind, systemic control trial. Reg. Anesth. Pain Med., 34 (2): 130-3.

11- HAIDER H. and MAHDI F.A.: The combination effect of lidocaine, ketamine and atracurium in intravenous regional anesthesia. Al Kindy Collegue Med. J. (KCMJ)., 9 (2): 61-3, 2013.

12- KAUL T., MITTAL B. and GUPTA S.: Comparison of lignocaine and ketamine as intravenous regional anaesthetics. Indian J. Anaesth., 41: 234-9, 1993.

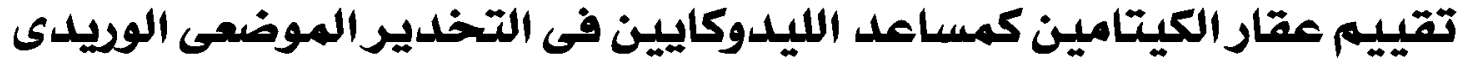

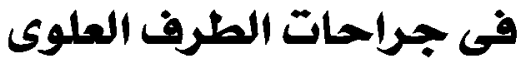

يعتبر التخدير الويدى طريقة بسيطة وفعالة لإجراء جراحات الطرف العلوى بالرغم من ذالك له بعض العيوب مثل الآلم الناتج عن نفخ الرباط

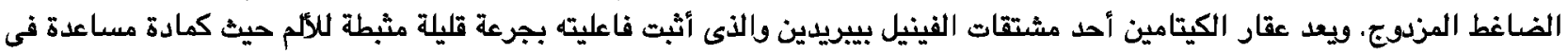

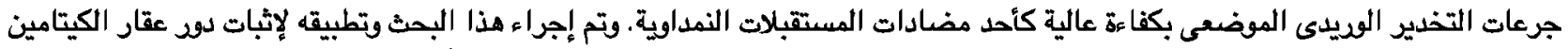

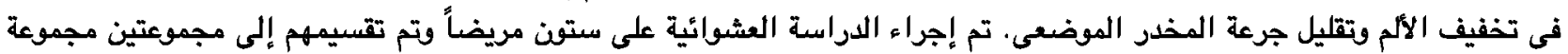

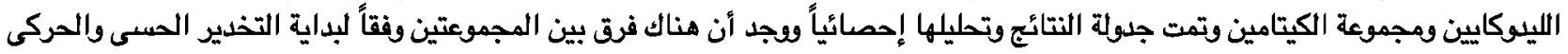

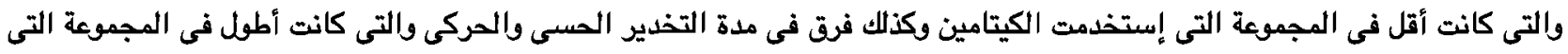

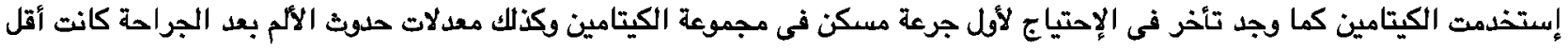

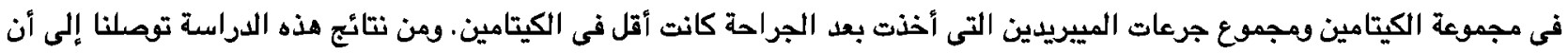

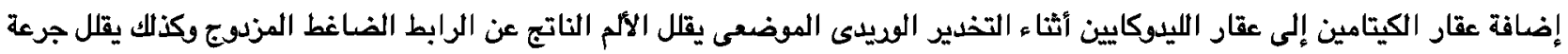
المخدر الموضعى كما أصن هنائ إطالة في مدة التخدير الصسى والعضلى وإنخفاض في معدلات الألم بعد العملية وتأخر لأول جرعة مسكن. 